\title{
Two-water-assisted racemization of the succinimide intermediate formed in proteins. A computational model study
}

\author{
Ohgi Takahashi \\ Tohoku Pharmaceutical University, Sendai, Japan; ohgi@,tohoku-pharm.ac.jp
}

Received 22 October 2013; revised 25 November 2013; accepted 1 December 2013

Copyright (C) 2013 Ohgi Takahashi. This is an open access article distributed under the Creative Commons Attribution License, which permits unrestricted use, distribution, and reproduction in any medium, provided the original work is properly cited.

\begin{abstract}
Racemization of aspartic acid (Asp) residues in proteins plays an important role in the molecular biology of aging. In the widely accepted mechanism of the Asp racemization, a succinimide (SI) intermediate is the species which actually undergo the direct racemization. In the present study, a two-water-assisted mechanism of the SI racemization was computationally investigated using a model compound in which an aminosuccinyl (Asu) residue is capped with acetyl and NMe groups on the $\mathrm{N}$ - and $\mathrm{C}$-termini, respectively. The two water molecules catalyze the enolization of the $\mathrm{H}_{\alpha}-\mathrm{C}_{\alpha}-\mathrm{C}=0$ portion in the Asu residue by mediating proton relay from the $\alpha$-carbon atom to the carboxyl oxygen atom. After the enolization, migration of the water molecules and conformational change lead to the mirror image of the initially formed enol two-water complex, and the racemization is completed by the following ketonization. The overall activation barrier $\left(28.2 \mathrm{kcal} \cdot \mathrm{mol}^{-1}\right)$ corresponds to the enolization and ketonization steps, and falls within the available experimental activation energies (21.4 $\left.29.0 \mathrm{kcal} \cdot \mathrm{mol}^{-1}\right)$. Therefore, the two-water-assisted mechanism investigated here is plausible for the in vivo and in vitro racemization reactions of the SI intermediates formed in peptides and proteins.
\end{abstract}

Keywords: Aspartic Acid Residue; Racemization; Nonenzymatic Reaction; Succinimide; Water Catalysis; Enolization; Computational Chemistry; Density Functional Theory

\section{INTRODUCTION}

Aspartic acid (Asp) residues (L-Asp residues) in pep- tides and proteins are prone to nonenzymatic racemization [1-3]. This reaction of Asp residues in long-lived proteins is a spontaneous, inevitable process during their natural aging and plays an important role in the molecular biology of aging [3-5]. The Asp racemization has also relevance to many age-related diseases such as cataract and Alzheimer's disease [3,4].

It has been widely accepted that a large part of the Asp racemization proceeds via the succinimide (SI) intermediate $[1,2,6,7]$. As shown in Figure 1, the SI intermediate, which is formed by intramolecular cyclization from the Asp residue (with release of a water molecule), is the actual species which undergo the direct racemization. Also, the structural isomerization to the $\beta$-form can accompany the racemization, since the SI has two carbonyl groups at which the reaction with water can occur.

At the physiological $\mathrm{pH}$ of 7.4, it is plausible that the racemization of the SI intermediate occurs via an enol species as shown in Figure 1 [7-9]. Note that, in the enol form, the $\alpha$-carbon atom has a planar configuration. Recently, the mechanism of the SI intermediate racemization via the enol form was computationally studied using a model compound in which an aminosuccinyl (Asu) residue is capped with a formyl ( $\mathrm{HCO}$ ) group and an $\mathrm{NMe}$ group (Nme) on the $\mathrm{C}$ - and $\mathrm{N}$-termini, respectively, and it was shown that two water molecules effectively catalyze the enolization process by mediating proton relay from the $\alpha$-carbon atom to the carboxyl oxygen atom [7]. In the present study, similar calculations were performed using a more suitable model compound shown in Figure 2. In this compound, the $\mathrm{N}$ - and $\mathrm{C}$-termini of an Asu residue are capped with acetyl (Ace) and Nme groups, respectively.

\section{METHOD}

All calculations were performed using Spartan '08 (Wavefunction, Inc., Irvine, CA, USA). Two water mole- 
<smiles>CNC(=O)[C@H](CC(=O)O)NCc1cccnc1</smiles><smiles>CNC(=O)C[C@H](NC)C(=O)O</smiles>

Figure 1. Succinimide-mediated reactions of an L-Asp residue.

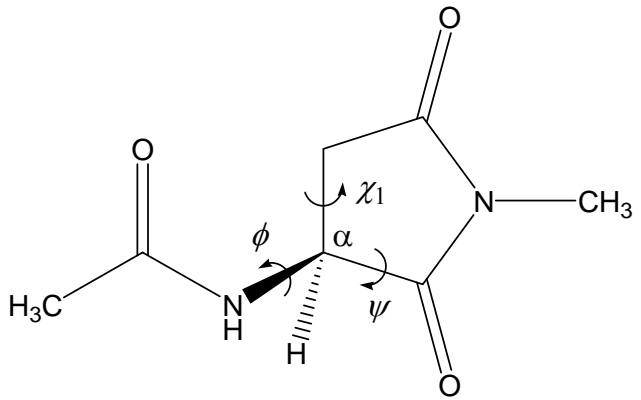

Figure 2. Model compound used in the present study (Ace-Asu-Nme). The dihedral angles $\phi(\mathrm{C}$ $\left.\mathrm{N}-\mathrm{C}_{\alpha}-\mathrm{C}\right)$ and $\psi\left(\mathrm{N}-\mathrm{C}_{\alpha}-\mathrm{C}-\mathrm{N}\right)$ characterize the mainchain conformation.

cules were placed to the model compound to form the reactant complex such that they make a bridge between the $\mathrm{C}_{\alpha}-\mathrm{H}_{\alpha}$ bond and the $\alpha$-carbonyl group of the Asu residue. Hereafter, the reactant complex is denoted as LSI (and its mirror image as D-SI). As in our previous studies [7-10], energy-minimum and transition state (TS) geometries were located by the density functional theory (DFT) calculation with the B3LYP functional and the $6-31+\mathrm{G}(\mathrm{d}, \mathrm{p})$ basis set. The relative energies were corrected for the zero-point energy (ZPE).

\section{RESULTS AND DISCUSSION}

Overall, the present results are very similar to those obtained previously using a more simple model compound [7].

The geometry of the reactant complex L-SI is shown in Figure 3. The two water molecules make a bridge between the $\mathrm{C}_{\alpha}-\mathrm{H}_{\alpha}$ bond and the $\alpha$-carbonyl group of the<smiles>CNC(=O)[C@H](CC(=O)O)NC</smiles><smiles>O=CC=CC(=O)O</smiles><smiles>CN[C@H]1CC(=O)N(C)C1=O</smiles>

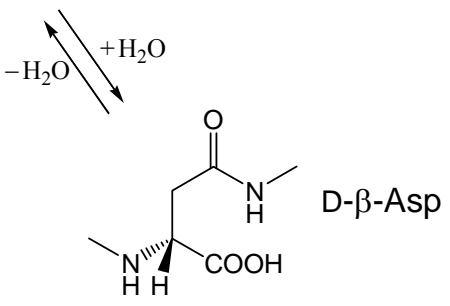

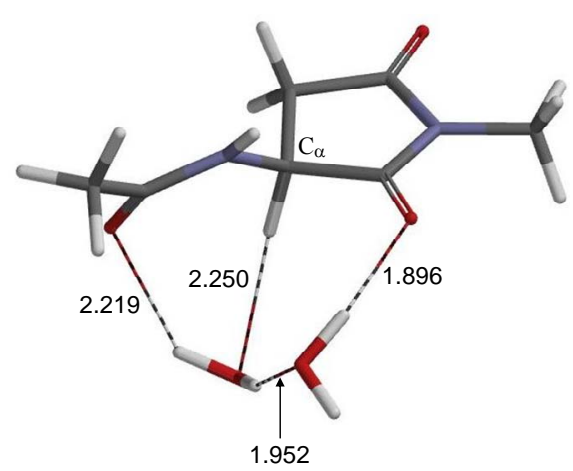

Figure 3. The geometry of the reactant complex L-SI $\left(\phi=-144^{\circ}, \psi=-139^{\circ}\right)$. Selected interatomic distances are shown in $\AA$.
Asu residue by a C-H $\cdots \mathrm{O}$ interaction (2.250 $\AA$ ) and hydrogen bonds to form a eight-membered cyclic structure between the model compound and the two water molecules. In addition, there is a weak hydrogen bond (2.219 $\AA$ ) between the oxygen atom of the Ace group ("neighboring residue") and the water molecule interacting with the $\mathrm{C}_{\alpha}-\mathrm{H}_{\alpha}$ bond.

The entire energy diagram for the conversion of L-SI to its mirror image D-SI is shown in Figure 4.

In the first step, a concerted bond reorganization involving a triple proton transfer occurs in the above-mentioned eight-membered cycle of L-SI via the transition state TS1 (Figure 5) to give an enol two-water complex EN1 (Figure 6). The activation barrier for this step was calculated to be $28.2 \mathrm{kcal} \cdot \mathrm{mol}^{-1}$. The hydrogen bond between the oxygen atom of the Ace group and one of the water molecules becomes considerably shorter in TS1 (1.706 $\AA)$, implying that this hydrogen bond has an im- 


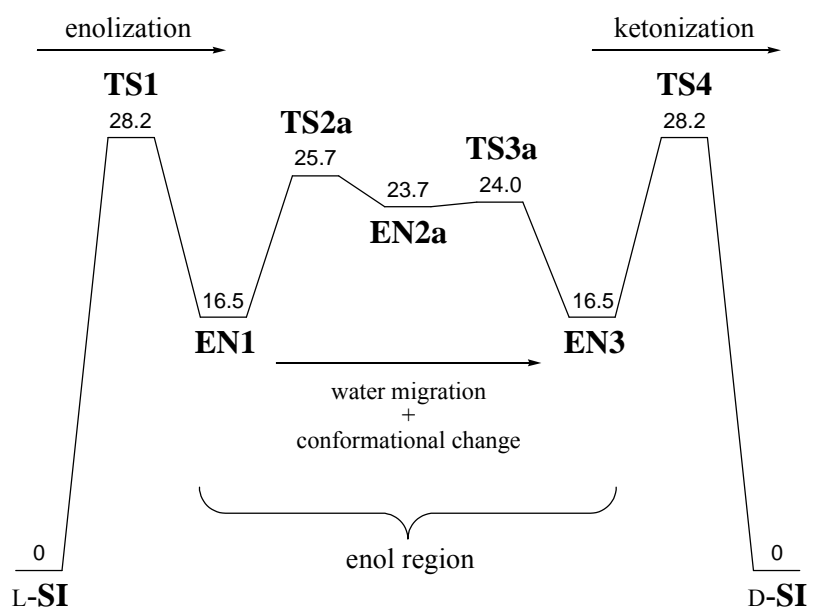

Figure 4. Energy diagram. ZPE-corrected energies relative to L-SI are shown in $\mathrm{kcal} \cdot \mathrm{mol}^{-1}$.

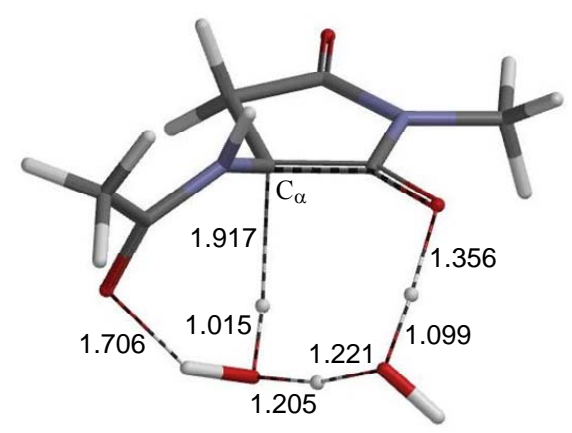

Figure 5. The geometry of TS1 $(\phi=$ $\left.-135^{\circ}, \psi=-150^{\circ}\right)$. Selected interatomic distances are shown in $\AA$.

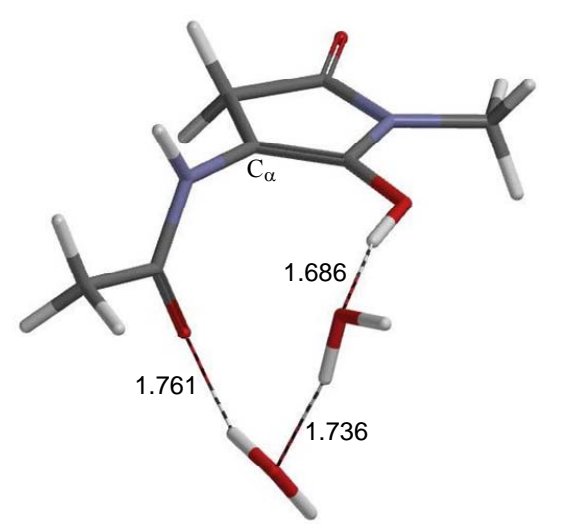

Figure 6. The geometry of EN1 $\left(\phi=-76^{\circ}\right.$, $\left.\psi=179^{\circ}\right)$. Hydrogen bond distances are shown in $\AA$.

portant role in stabilizing the transition state. EN1 is higher in energy than L-SI by $16.5 \mathrm{kcal} \cdot \mathrm{mol}^{-1}$. The dihedral angle $\phi$ changes largely from $-144^{\circ}$ to $-76^{\circ}$ by this enolization step.

From EN1, there exist two energetically equivalent routes, Route A and Route B, which are related by re- flection, to reach its mirror image EN3 $\left(\phi=76^{\circ}, \psi=\right.$ $-179^{\circ}$ ). In Route A (Figure 4), migration of the two water molecules and a conformational change from $\phi=$ $-76^{\circ}$ to $\phi=-150^{\circ}$ first occurs though the transition state TS2a (Figure 7) leading to EN2a (Figure 8), followed by a conformational change to $\phi=76^{\circ}$ through the transition state TS3a (Figure 9) leading to EN3. In Route B,

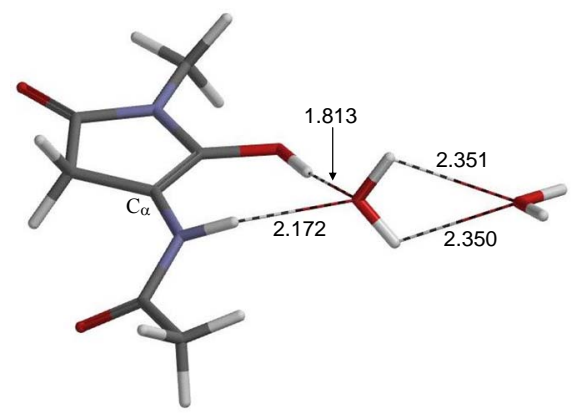

Figure 7. The geometry of TS2a $\left(\phi=-147^{\circ}\right.$, $\left.\psi=-176^{\circ}\right)$. Selected interatomic distances are shown in $\AA$.

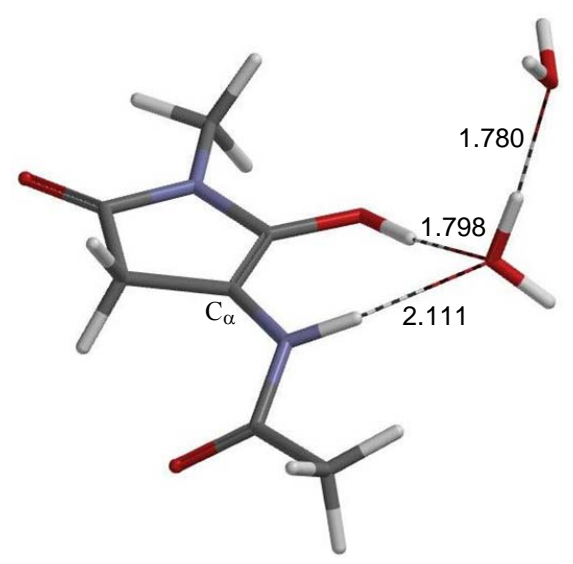

Figure 8. The geometry of EN2a ( $\phi=$ $-150^{\circ}, \psi=-176^{\circ}$ ). Hydrogen bond distances are shown in $\AA$.

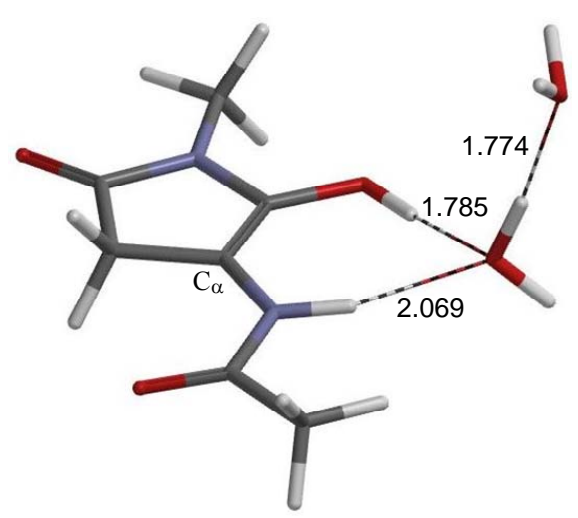

Figure 9. The geometry of TS3a $\left(\phi=-175^{\circ}\right.$, $\left.\psi=-179^{\circ}\right)$. Hydrogen bond distances are shown in $\AA$. 
a conformational change to $\phi=150^{\circ}$ occurs first, and the water migration and conformational change leading to EN3 follow. The stereoinversion of L-SI is completed by the ketonization (i.e., the reverse reaction of enolization) of EN3 catalyzed by the two water molecules to give DSI $\left(\phi=144^{\circ}, \psi=139^{\circ}\right)$. The transition state of this final step is denoted as TS4 in Figure 4. It should be noted that, in EN3, the two water molecules reside on the opposite side of the five-membered ring compared to EN1.

The overall activation barrier is $28.2 \mathrm{kcal} \cdot \mathrm{mol}^{-1}$, corresponding to the initial enolization and the final ketonization steps. This value falls within the experimental activation energies $\left(21.4-29.0 \mathrm{kcal} \cdot \mathrm{mol}^{-1}\right)$ determined by Arrhenius plots for systhetic peptides corresponding to fragments of $\alpha \mathrm{A}$-crystalline and elastin $[11,12]$. This implies that the two-water-assisted racemization mechanism investigated here may be one of those which actually occur in vivo and in vitro for peptides and proteins.

\section{CONCLUSION}

A two-water-assisted mechanism of the SI racemization in the formation of D-Asp residues was computationally investigated using Ace-Asu-Nme as a model compound. The energetic results were very similar to those of the previous study [7] using a more simple model compound. The calculated activation barrier fairly agreed with the available experimental results. Therefore, it is highly plausible that the two-water-assisted mechanism of the SI racemization actually occurs in peptides and proteins. Water, while indispensable for life, may also catalyze the biological reaction which is related to aging. Mechanisms where more than two water molecules catalyze the SI racemization can also be conceivable. Such mechanisms will be investigated in the near future.

\section{REFERENCES}

[1] Geiger, T. and Clarke, S. (1987) Deamidation, isomerization, and racemization at asparaginyl and aspartyl residues in peptides. Succinimide-linked reactions that contribute to protein degradation. Journal of Biological Chemistry, 262, 785-794. http://www.jbc.org/content/262/2/785.short

[2] Stephenson, R.C. and Clarke, S. (1989) Succinimide formation from aspartyl and asparaginyl peptides as a model for the spontaneous degradation of proteins. Journal of Biological Chemistry, 264, 6164-6170. http://www.jbc.org/content/264/11/6164.short
[3] Ritz-Timme, S. and Collins, M.J. (2002) Racemization of aspartic acid in human proteins. Ageing Research Reviews, 1, 43-59. http://dx.doi.org/10.1016/S0047-6374(01)00363-3

[4] Fujii, N. (2005) D-Amino acid in elderly tissues. Biological \& Pharmaceutical Bulletin, 28, 1585-1589. http://dx.doi.org/10.1248/bpb.28.1585

[5] Motoie, R., Fujii, N., Tsunoda, S., Nagata, K., Shimo-oka, T., Kinouchi, T., Fujii, N., Saito, T. and Ono, K. (2009) Localization of $\mathrm{D}$ - $\beta$-aspartyl residue-containing proteins in various tissues. International Journal of Molecular Sciences, 10, 1999-2009. http://dx.doi.org/10.3390/ijms10051999

[6] Radkiewicz, J.L., Zipse, H., Clarke, S. and Houk, K.N. (1996) Accelerated racemization of aspartic acid and asparagine residues via succinimide intermediates: An $a b$ initio theoretical exploration of mechanism. Journal of the American Chemical Society, 118, 9148-9155. http://dx.doi.org/10.1021/ja953505b

[7] Takahashi, O., Kobayashi, K. and Oda, A. (2010) Modeling the enolization of succinimide derivatives, a key step of racemization of aspartic acid residues: Importance of a two- $\mathrm{H}_{2} \mathrm{O}$ mechanism. Chemistry \& Biodiversity, 7, 13491356. http://dx.doi.org/10.1002/cbdv.200900296

[8] Takahashi, O., Kobayashi, K. and Oda, A. (2010) Computational insight into the mechanism of serine residue racemization. Chemistry \& Biodiversity, 7, 1625-1629. http://dx.doi.org/10.1002/cbdv.200900297

[9] Takahashi, O., Kobayashi, K. and Oda, A. (2010) Computational modeling of the enolization in a direct mechanism of racemization of the aspartic acid residue. Chemistry \& Biodiversity, 7, 1630-1633. http://dx.doi.org/10.1002/cbdv.200900298

[10] Takahashi, O. and Oda, A. (2012) Amide-iminol tautomerization of the C-terminal peptide groups of aspartic acid residues. Two-water-assisted mechanism, cyclization from the iminol tautomer leading to the tetrahedral intermediate of succinimide formation, and implication to peptide group hydrogen exchange. In: Jones, J.E. and Morano, D.M., Eds., Tyrosine and Aspartic Acid: Properties, Sources and Health Benefits, Nova Science Publishers, New York, 131-147.

https://www.novapublishers.com/catalog/product info.ph p?products $\mathrm{id}=35660$

[11] Fujii, N., Momose, Y. and Harada, K. (1996) Kinetic study of racemization of aspartyl residues in model peptides of $\alpha \mathrm{A}$-crystallin. International Journal of Protein Research, 48, 118-122. http://dx.doi.org/10.1111/j.1399-3011.1996.tb00821.x

[12] Kuge, K., Fujii, N., Miura, Y., Tajima, S. and Saito, T. (2004) Kinetic study of racemization of aspartyl residues in synthetic elastin peptides. Amino Acids, 27, 193-197. http://dx.doi.org/10.1007/s00726-004-0107-3 